\title{
Can I quote you on that?
}

\begin{abstract}
Just as a simple phrase can become convoluted in the childhood game of Telephone, research findings can be distorted in the lay press. Journalists and scientists themselves must share the responsibilities of better explaining and interpreting science in an accessible and meaningful context for nonspecialist readers.
\end{abstract}

The public primarily learns about medical research through television, print media, radio, and the Internet. The reciprocal relationship in which scientists assist the media to inform the public while journalists help garner public recognition of their research can be enriching but at times disheartening. As a case in point, the press coverage of a recent JCI article was mixed: while the vast majority of news sources accurately translated the findings, one particular reporter was dramatically off course. The JCI research article reported, among other findings, that administration of tetrahydrocannabinol (the active ingredient of marijuana) either prevented or caused early implantation of embryos in mice (1). Rather than reporting that marijuana use could lead to ectopic pregnancy and/or impaired fertility if this were found to hold true in humans, one newsstand science periodical chose to paint marijuana as an effective contraceptive: "using cannabis around the time of conception can prevent pregnancy ... [making] a not-so-bad case for marijuana as birth control" (2). In light of such irresponsible reporting, it is no wonder scientists often denounce the press for misrepresenting research, touting cures, and lending credibility to fringe scientific viewpoints. While journalists are often required to write about or speak to subjects for which they have had little or no formal training, this does not forgive reckless reporting at its most flagrant. Consequently, many researchers are reluctant to spend time disseminating their work beyond the traditional avenue of exposure - publication in peer-reviewed scientific journals. Of course, one bad apple does not spoil the bunch, and scientists must work together with journalists to best communicate how critical advances in medical science impact human health.

Medical research is largely funded by taxpayers, and as most are not reading scientific research journals, scientists should consider their interaction with the press a return on the public's investment. Responsible reporting can serve as a good platform to promote the benefits of medical research, raise the profile of scientific issues, and advocate to government the need for ongoing financial support. A dialogue exists between scientists and policy makers, and public opinion can significantly impact science policy. Consider the value added to a study by exposure in the press. While initial attention received may be overwhelming for researchers involved, news coverage disseminates results to both the lay and scientific communities, and studies publicized in high-profile news sources seem to be more frequently cited than their unpublicized counterparts. Furthermore, establishing a dialogue between scientists and society can help counteract the public's misconceptions about a field of research and increase institutional visibility, the trickle-down effects of which can include increased recruitment for clinical trials or new collaborations. Many researchers have found themselves heralded as scientific superstars, achieving long-lasting fame.

With the increased visibility a scientist may enjoy from being featured in the press comes an increased responsibility to ensure that results are reported in an accurate, balanced manner that steers clear of sensationalistic notions. The onus is on the scientist and journalist to not overinterpret conclusions, extrapolate animal data to humans, or underrepresent associated risks or limitations in an effort to portray applications or benefits in a way that suggests they are more immediate or general in nature than they may well be.

Not all scientists have an interest in being seen and heard, perhaps believing that trumpeting success is unseemly or that given the competitive nature of science and increasing corporate ties, heightened exposure may place investments, collaborations, or funding at risk. Hand in hand with an increased public profile comes a greater chance of receiving negative publicity; for example, if proposed therapeutics do not pan out. In addition, authors of studies published in the JCI have requested that a press release discussing details of their work in animals not be released to the media for fear of triggering an outcry from animal rights activists, despite having received appropriate ethical approval from their institution.

Relations with the press should be considered part and parcel of scientists' responsibilities, alongside grant writing and student mentoring. However, unlike political figures, scientists are not often called upon to spin their work for the press. Should scientists look to the academic system to provide better instruction as to how to describe research in simpler terms? Scientists are encouraged to assess to what end a journal highlights published research for the lay press, consider this prior to submission, and work with institutional public affairs offices toward preparing press releases. Many institutions have recently begun to offer access to trained communications staff to coach potential interviewees on how to handle press interviews and to avoid being misquoted.

In order for the scientist-journalist symbiosis to succeed, scientists must carefully consider their audience and determine the most appropriate angle for presenting how their work impacts everyday life, in simple language devoid of jargon. In turn, journalists must gather the facts, present them accurately, and always remain acutely aware of their social responsibility, which as the aforementioned instance unfortunately reinforces is not always the case. Readers are strongly encouraged to be prudent in their choice of birth control. And yes, you can quote me on that.

\section{Brooke Grindlinger Science Editor}

1. Wang, H., et al. 2006. Fatty acid amide hydrolase deficiency limits early pregnancy events. J. Clin. Invest. 116:2122-2131. doi:10.1172/JCI28621.

2. Wittlin, M. 2006. Weeding out the runts. Seed Magazine. August 8. http://www.seedmagazine.com/ news/2006/08/i_cant_believe_its_science_728.php. 